\title{
锂硫电池电解质研究进展
}

\author{
金朝庆* 谢凯* 洪晓斌 \\ (国防科技大学航天科学与工程学院 材料科学与工程系 长沙 410073)
}

\begin{abstract}
摘要 锂硫电池由于其高能量密度(理论高达 $2600 \mathrm{Wh} / \mathrm{kg}$ )、低成本、环境友好等优点而广受关注. 但是锂硫电池仍存 在正极活性物质利用率低、循环性能差等问题. 造成这些问题的主要原因是易溶于有机电解液的中间产物聚硫锂 $\mathrm{Li}_{2} \mathrm{~S}_{n}$ $(4 \leqslant n \leqslant 8)$ 和不溶于有机电解液的硫化锂造成的. 简要介绍了锂硫电池体系的主要问题, 并结合本研究小组的研究, 对 锂硫电池用电解质体系从有机电解液组成、电解液添加剂、聚合物电解质和无机固体电解质等方面进行了详细的综述, 最后对电解质的发展前景进行了展望.
\end{abstract}

关键词 锂硫电池; 有机电解液; 离子液体电解质; 电解液添加剂; 有机电解质; 无机电解质

\section{Review of Electrolyte for Lithium Sulfur Battery}

\author{
Jin, Zhaoqing* Xie, Kai* Hong, Xiaobin \\ (Department of Material Science and Engineering, College of Aerospace Science and Engineering, National University of \\ Defense Technology, Changsha 410073)
}

\begin{abstract}
Of the high energy density chemical power systems currently being considered, lithium/sulfur (Li/S) batteries which use elemental sulfur as the cathode and lithium metal as the anode, are attracting increased attention in recent decades. $\mathrm{Li} / \mathrm{S}$ batteries have a high energy density $(2600 \mathrm{Wh} / \mathrm{kg}$ in theoretical, about $400 \mathrm{Wh} / \mathrm{kg}$ in practice nowadays), consist of abundant raw materials, are low cost and environmentally friendly. Although the rechargeable Li/S batteries possess more advantages over the conventional lithium ion batteries, the practical use faces with a variety of problems such as low utilization of sulfur and bad cycle life. Central to the operation of Li/S batteries are polysulfide anions $\left.\left(\mathrm{S}_{n}^{2-}, 4 \leqslant n \leqslant 8\right)\right]$, which are intermediate products generated during the electrochemical reduction process. These anions have high solubility in organic electrolytes. On the one hand, these anions typically diffuse to the lithium anode according to a concentration gradient and directly react with the anode. This diffusion causes an internal shuttle phenomenon and significantly corrodes the anode, which decreases active material utilization during the discharge process and reduces its cycle life. On the other hand, there are residual $\mathrm{Li}_{2} \mathrm{~S}_{2}$ and/or $\mathrm{Li}_{2} \mathrm{~S}$ on the surface of sulfur cathode and $\mathrm{Li}$ anode even at $100 \%$ depth of charge. The formation of $\mathrm{Li}_{2} \mathrm{~S}_{2}$ and $\mathrm{Li}_{2} \mathrm{~S}$ increasing with cycling results in active material loss. These drawbacks have seriously retarded industrial production of $\mathrm{Li} / \mathrm{S}$ batteries. In this paper, combining with the works of our research team, the main research directions and the latest development of the electrolyte to enhance the cycle performance of Li-S batteries are reviewed from the aspects of the composition of the liquid electrolyte, the additives in liquid electrolyte, the polymer electrolyte and the inorganic electrolyte. At the meanwhile, the principle, the preparation of electrolyte, the influence on the performance of Li-S batteries, and problem in each research are analyzed. Finally, the further development of the electrolyte in Li-S battery is discussed.

Keywords lithium sulfur battery; liquid electrolyte; ionic liquid electrolyte; additive in electrolyte; polymer electrolyte; inorganic electrolyte
\end{abstract}

\section{1 引言}

随着移动通讯，电子仪表及电动工具等便携式电子 设备的迅速发展，以及人们节能环保意识的提高，可多 次充放电的二次电池得到了广泛应用 ${ }^{[1,2]}$. 其中, 出现于 20 世纪 90 年代的锂离子二次电池是目前世界上公认的 新一代化学电源, 已成功商品化并在便携式设备领域中 飞速发展. 但在电动汽车、航空航天和国防装备等领域, 目前商品化锂离子二次电池受限于理论容量, 无法进一 步显著提高其能量密度, 已远不能满足技术发展的需 求 $^{[3]}$. 因此, 需要急切研究开发具有更高能量密度、更长 循环寿命、低成本和环境友好等特征的新型化学电源.
以金属锂为负极, 单质硫为正极活性物质的锂硫二 次电池(简称锂硫电池), 理论能量密度高达 $2600 \mathrm{Wh} / \mathrm{kg}$, 实际可实现的能量密度为 $500 \mathrm{Wh} / \mathrm{kg}$, 且单质硫成本 低、对环境友好, 符合电动汽车、空间技术和国防装备 等领域对动力电池需求 ${ }^{[4-6]}$. 表 1 对比了传统锂离子二 次电池与锂硫电池在比容量、能量密度等方面的性能, 由于锂-硫组合是所有已知化学可逆系统中能量密度最 高的固态电极组合, 即使锂硫电池中硫基复合正极中单 质硫的重量百分比仅为 $50 \%$, 其正极理论比容量仍高达 $836 \mathrm{mAh} / \mathrm{g}$, 能量密度达 $760 \mathrm{Wh} / \mathrm{kg}$, 远高于一般锂离子 二次电池的过渡金属氧化物基正极材料体系 ${ }^{[7,8]}$.

*E-mail: jinzhaoqing1001@gmail.com; Kai_Xie@163.com

Received October 27, 2013; published December 26, 2013. 
锂硫电池的高容量和可充放电性能来源于 $\mathrm{S}_{8}$ 分子 中 $\mathrm{S}-\mathrm{S}$ 键的电化学断裂和重新键合. 其中单质硫与金 属锂的电化学反应包括多步骤氧化还原反应, 同时伴随 着硫化物相转移过程. 在放电过程中, 固相单质硫 $\mathrm{S}_{8(\mathrm{~s})}$ 通过导电剂获得 2 个电子, 逐步被还原为聚硫离子 $\mathrm{S}_{n}^{2-}$ $(4 \leqslant n \leqslant 8)$, 并与 $\mathrm{Li}^{+}$结合生成放电中间产物聚硫锂 $\mathrm{Li}_{2} \mathrm{~S}_{n}$ $(4 \leqslant n \leqslant 8)$. 这些中间产物易溶于电解液, 将从正极结构 中通过电解液向锂负极方向扩散. 随着放电过程的深 入, $\mathrm{Li}_{2} \mathrm{~S}_{n}(4 \leqslant n \leqslant 8)$ 进一步被还原, 生成放电终产物 $\mathrm{Li}_{2} \mathrm{~S}_{2}$ 和 $\mathrm{Li}_{2} \mathrm{~S}$. 而放电终产物在电解液中溶解度极低. 正是由 于锂硫电池在电化学反应过程中产生的中间产物长链 聚硫锂 $\mathrm{Li}_{2} \mathrm{~S}_{n}(4 \leqslant n \leqslant 8)$ 易溶于有机电解液以及最终产物 $\mathrm{Li}_{2} \mathrm{~S}_{2} / \mathrm{Li}_{2} \mathrm{~S}$ 不溶于有机电解液的特性所造成锂硫电池循 环性能差、库仑效率低、自放电率高等问题, 延缓了其 实用化的步伐 ${ }^{[9,10]}$.

第一, 溶解于有机电解液的 $\mathrm{Li}_{2} \mathrm{~S}_{n}(4 \leqslant n \leqslant 8)$ 在浓度 梯度存在的情况下, 将在有机电解液中自由扩散, 从而 产生 “飞梭现象”, 最终导致锂硫电池库仑效率下降 ${ }^{[11]}$.

第二, 由于 $\mathrm{Li}_{2} \mathrm{~S}_{2}$ 和 $\mathrm{Li}_{2} \mathrm{~S}$ 不溶于电解液, 它们将分 别在正负极表面沉积. 这一方面改变了正负极的形貌, 破坏了电极/电解液之间的界面状态; 另一方面, 沉积于 正极表面的 $\mathrm{Li}_{2} \mathrm{~S}_{2}$ 和 $\mathrm{Li}_{2} \mathrm{~S}$ 有一部分会与导电剂分离, 而 沉积于负极表面的 $\mathrm{Li}_{2} \mathrm{~S}_{2}$ 和 $\mathrm{Li}_{2} \mathrm{~S}$ 在富锂状态下难以完全 被电化学氧化成为 $\mathrm{Li}_{2} \mathrm{~S}_{n}(4 \leqslant n \leqslant 8)$, 从而造成活性物质 失活. 这些都将导致锂硫电池的性能下降 ${ }^{[12 ~ 14]}$.

目前, 锂硫电池的大部分研究都集中于正极材料的 结构研究, 以期通过正极的特殊结构减少 $\mathrm{Li}_{2} \mathrm{~S}_{n}(4 \leqslant n \leqslant$ 8) 向电解液的溶解 ${ }^{[15 ~ 17]}$. 但是, 电解质对锂硫电池的性 能的影响同样不可忽视. 本文主要综述和分析了近年来 研究人员在锂硫电池电解质方面所开展的基础性研究 和取得的突破性进展, 从优化有机电解液组成, 电解液 添加剂, 聚合物电解质, 无机固体电解质等 4 个方面, 深入分析使用不同电解质的锂硫电池的反应机理、充放 电性能，并对其进一步发展和应用予以展望.

\section{2 优化有机电解液组成}

单质硫在非质子溶剂中的氧化还原反应始自 1970 年, 美国加州大学 Sawyer 研究小组 ${ }^{[18]}$ 使用金电极对单 质硫在非质子性溶剂二甲基亚砜(DMSO)中的电化学还 原过程进行了分析, 采用循环伏安法 $(\mathrm{CV})$ 等方法测得了 单质硫的氧化还原电位, 并且研究了 $\mathrm{S}_{8}$ 分子在金电极 上的多步还原过程. 1973 年，该研究小组 ${ }^{[19]}$ 对单质硫的 电化学还原进行了更加深入的研究, 提出硫在非质子性 溶剂中选择性还原以及鉴别不同链长 $\mathrm{Li}_{2} \mathrm{~S}_{n} \quad(4 \leqslant n \leqslant 8)$ 的 基本原则, 为锂硫电池的发展提供了坚实的理论基础.

早期对锂硫电池的研究始于 20 世纪 70 年代, $\mathrm{RaO}^{[20]}$ 以及 Nole 等 ${ }^{[21]}$ 分别对锂硫电池进行了研究. 他们将单 质硫负载到集流体上, 以锂为负极进行放电实验，但放 电容量、放电效率都很低. 他们都认为是由于 $\mathrm{S}_{8}$ 分子被 还原成 $\mathrm{S}_{n}^{2-}(4 \leqslant n \leqslant 8)$, 溶解到有机电解液中进而与锂负 极反应，发生严重的自放电而造成的. 因此他们都主张 在锂硫电池中使用抑制 $\mathrm{S}_{n}^{2-}(4 \leqslant n \leqslant 8)$ 溶解的有机电解 液. 而 Rauh 等 ${ }^{[22]}$ 则认为, 由于单质硫及其最终放电产 物 $\mathrm{Li}_{2} \mathrm{~S}$ 都是电子绝缘体, 导致锂硫电池性能差的原因并 不是 $\mathrm{S}_{n}^{2-}(4 \leqslant n \leqslant 8)$ 的溶解, 而恰恰相反, $\mathrm{S}_{n}^{2-}(4 \leqslant n \leqslant 8)$ 的溶出有利于尚未反应的单质硫与导电剂的接触, 从而 可以提高活性物质硫的利用率. 他们研究了将单质硫完 全溶解到 $1 \mathrm{~mol} / \mathrm{L} \mathrm{LiAsF}_{6} /$ 四氢呋喃 $(\mathrm{THF})$ 电解液中的锂 硫电池电化学行为. 结果表明, 活性物质全部或部分的 溶解有助于硫利用率的提高, 在 $50{ }^{\circ} \mathrm{C}$ 下 $\sim 4 \mathrm{~mA} / \mathrm{cm}^{2}$ 电流密度下放电, 硫的利用率能达 $75 \%$.

随后, 各国研究人员重点对能溶解 $\mathrm{S}_{n}^{2-}(4 \leqslant n \leqslant 8)$ 的 有机电解液进行了研究.

1988 年, Peled 等 ${ }^{[23]}$ 采用 $\mathrm{CV}$ 研究了 $0.4 \mathrm{mmol} / \mathrm{L}$ $\mathrm{Li}_{2} \mathrm{~S}_{n}(6 \leqslant n \leqslant 12)$ 在 $0.8 \mathrm{~mol} / \mathrm{L} \mathrm{LiClO}_{4} / \mathrm{THF}$ 溶液中的多步 氧化还原机理. 但由于还原产物 $\mathrm{S}_{2}^{2-}$ 或 $\mathrm{S}^{2-}$ 不溶于 THF, 在接下来几次的 $\mathrm{CV}$ 循环中, 还原峰出现较大的偏移. 1989 年, 该研究小组 ${ }^{[24]}$ 在此基础上, 研究了在 $\mathrm{LiClO}_{4} /$

表 1 传统锂二次电池正极与硫正极性能比较 ${ }^{[7,8]}$

Table 1 Comparison of Li-ion batteries with transition metal oxide cathodes and $\mathrm{S}$ cathode

\begin{tabular}{|c|c|c|c|c|c|c|c|}
\hline Cathode & 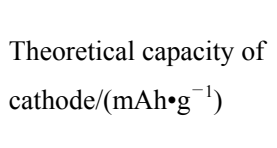 & $\begin{array}{l}\text { Estimated capacity of } \\
\text { cathode } /\left(\mathrm{mAh} \cdot \mathrm{g}^{-1}\right)\end{array}$ & $\begin{array}{l}\text { Estimated energy } \\
\text { density of cathode/ } \\
\left(\mathrm{Wh} \bullet \mathrm{kg}^{-1}\right)\end{array}$ & Anode &  & $\begin{array}{l}\text { Discharge potential } \\
\text { of a full cell/V }\end{array}$ & $\begin{array}{l}\text { Estimated energy density } \\
\text { of a full cell }{ }^{b} /\left(\mathrm{Wh} \cdot \mathrm{kg}^{-1}\right)\end{array}$ \\
\hline Sulfur & 1672 & $1000^{a}$ & 2600 & $\mathrm{Li}$ & 3829 & 2.1 & $2447^{c}$ \\
\hline $\mathrm{C} / \mathrm{S}-60 \%$ & 1005 & 600 & 1260 & $\mathrm{Li}$ & 3829 & 2.1 & 1090 \\
\hline $\mathrm{C} / \mathrm{S}-50 \%$ & 836 & 500 & 1050 & $\mathrm{Li}$ & 3829 & 2.1 & 760 \\
\hline $\mathrm{LiFePO}_{4}$ & 170 & 160 & 552 & $\mathrm{Li} / \mathrm{C}_{6}$ & $3829 / 372$ & $3.45 / 3.35$ & $483 / 378^{d}$ \\
\hline $\mathrm{LiMn}_{2} \mathrm{O}_{4}$ & 148 & 110 & 440 & $\mathrm{Li} / \mathrm{C}_{6}$ & $3829 / 372$ & $4.0 / 3.9$ & $394 / 331$ \\
\hline $\mathrm{LiCoO}_{2}$ & 274 & 140 & 518 & $\mathrm{Li} / \mathrm{C}_{6}$ & $3829 / 372$ & $3.7 / 3.6$ & $456 / 366$ \\
\hline
\end{tabular}

$\overline{{ }^{a}}$ Estimated capacity of bare sulfur is assumed to be $1000 \mathrm{mAh} / \mathrm{g} .{ }^{b}$ Based on active mass (anode and cathode) only, excluding electrolyte, separator and other components. ${ }^{c}$ When Li metal is used as an anode, the excess $\mathrm{Li}$ is needed in a real cell, thus decreasing the energy density. ${ }^{d}$ When silicon or tin based material is used as an anode, the estimated energy density of a cell is between lithium anode and graphite anode. 
$\mathrm{THF}+$ 甲苯 $(\mathrm{TOL})$ 有机电解液中加入 1,3-二氧戊烷 (DOL) 对锂硫电池的影响. 实验证明, 加入 DOL 后, 虽 然有机电解液的电导率增加了一个数量级且减少了电 解液对锂负极的腐蚀, 但是过多的 DOL 使正极中硫的 利用率有所降低, 从使用 THF+TOL (1:1 by volume) 电解液时的 95\%降至使用 THF+TOL+DOL $(1: 1: 8$ by volume) 电解液时的 50\%, 其原因是过多加入的 DOL 使最终放电产物从 $\mathrm{Li}_{2} \mathrm{~S}$ 变为 $\mathrm{Li}_{2} \mathrm{~S}_{2}$.

随着对锂硫电池原理的深入研究, 研究人员逐渐认 识到适合锂硫电池的有机电解液的基本特征: (1)具有高 的化学稳定性和离子传导性. (2)对 $\mathrm{Li}_{2} \mathrm{~S}_{n}(4 \leqslant n \leqslant 8)$ 具有 一定溶解度. (3) 与锂电极相容性好. 但是当 $\mathrm{Li}_{2} \mathrm{~S}_{n}(4 \leqslant$ $n \leqslant 8)$ 溶解在电解液中后, 有机电解液黏度会增大, 将导 致电解液的离子传导性降低, 因此单溶剂组分的电解液 体系难以满足以上条件.

经过长时间的研究积累, 研究人员逐渐发现使用链

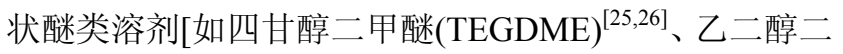
甲醚 $(\mathrm{DME})^{[27,28]}$ 、二乙二醇二甲醚 $(\mathrm{DG})^{[29]}$ 、四乙醇二甲 醚 $(\mathrm{TG})^{[30]}$ 等] 与环状醚类溶剂[如 $\mathrm{DOL}^{[26,28]}$ 、THF、甲基 乙基砜(EMS $)^{[17]}$ 等]的混合溶剂作为锂硫电池的有机电 解液能够得到较好的性能, 特别是在首次循环中有较高 的单质硫利用率. 其中, 有机电解液中链状醚类溶剂对 $\mathrm{Li}_{2} \mathrm{~S}_{n}(4 \leqslant n \leqslant 8)$ 具有高溶解度, 环状醚类在降低电解液 黏度的同时可以在锂电极上沉积形成保护层, 降低锂电 极的腐蚀 ${ }^{[31}$.

2002 年, Chang 等 ${ }^{[25]}$ 首先报道了 TEGDME 与 DOL 的混合溶剂作为锂硫电池的有机电解液, 对该电解液体 系的电导率、黏度等方面的研究发现, 当 DOL 与 TEGDME 质量比为 $70: 30$ 时, 电解液的离子电导率最 高, 黏度最低, 且用于锂硫电池后在电池首次放电时拥 有最高的活性物质利用率 $(60 \%)$, 但没有报道该电池循 环性能数据.

2004 年, Kim 等 ${ }^{[32]}$ 研究了 $1 \mathrm{~mol} / \mathrm{L}$ LiTFSI/DME+ $\mathrm{DG}+\mathrm{DOL}$ 有机电解液中的溶剂组成对锂硫电池的放电 性能影响, 并通过统计学方法得到了优化的溶剂组成, 当 $D M E: D G: D O X=4: 4: 2$ (by volume) 时, 锂硫电 池具有最大的首次放电比容量和放电电压.

2010 年, Wang 等 ${ }^{[33]}$ 对 $1 \mathrm{~mol} / \mathrm{L} \mathrm{LiClO}_{4} / \mathrm{DME}+\mathrm{DOL}$ 电解液体系研究发现, 过量的 DME 或 DOL 均会导致锂 硫电池循环性能变差, 原因是过多 DME 会增加电池界 面阻抗, 而过多 DOL 则导致电解液对 $\mathrm{S}_{n}^{2-}(4 \leqslant n \leqslant 8)$ 溶 解度不够. 二者最佳配比为 DME 与 DOL 质量比为 2 : 1 , 此时硫正极的首次放电比容量为 $1200 \mathrm{mAh} / \mathrm{g}$, 经 20 次循环后的可逆容量为 $800 \mathrm{mAh} / \mathrm{g}$.

2011 年, Abruña 等 ${ }^{[34]}$ 详细考察了 3 种不同锂盐 $\left(\mathrm{LiPF}_{6}, \mathrm{LiTFSI}\right.$ 和 $\left.\mathrm{LiSO}_{3} \mathrm{CF}_{3}\right)$ 以及不同有机溶液对锂硫电 池性能的影响. 研究发现不同锂盐种类对锂硫电池的性 能影响不大, 使用 3 种不同锂盐但锂盐浓度、溶剂均相 同的电解液的锂硫电池在充放电电压平台、充放电比容
量等方面几乎没有差别. 溶剂种类则是影响锂硫电池性 能的关键性因素. 锂硫电池在使用 TEGDME, DOL+ DME $(1: 1$ by weight), EMS +DOL +DME $(4: 1: 1$ by weight)等有机电解液时具有良好的性能, 首次放电比容 量均达到 $1000 \mathrm{mAh} / \mathrm{g}$. 而在使用含酯类溶剂的电解液 时, 如 PC $+\mathrm{EC}+\mathrm{DEC}(1: 4: 5$ by weight), EMC $+\mathrm{DEC}$ ( $8: 1$ by weight), 循环性能很差, 如图 1 所示. 通过原 位 X 射线吸收光谱(in-situ X-ray absorption spectroscopy, $\mathrm{XAS}$ )研究发现造成锂硫电池性能差别的原因是 $\mathrm{Li}_{2} \mathrm{~S}_{n}$ $(4 \leqslant n \leqslant 8)$ 不溶于酯类溶剂, 甚至会与酯类溶剂发生不良 的副反应, 不利于正常的电化学反应.

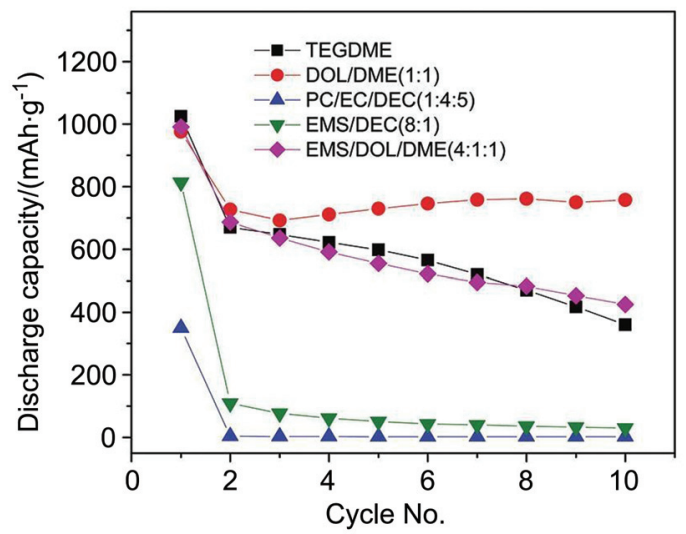

图 1 锂硫电池在不同电解液中循环性能的比较 ${ }^{[34]}$

Figure 1 Cycling performance of Li-S cells in $1.0 \mathrm{~mol} / \mathrm{L} \mathrm{LiCF}_{3} \mathrm{SO}_{3}$ with different solvents ${ }^{[34]}$

2013 年, Barchasz 等 ${ }^{[26]}$ 全面考察了不同锂盐(LiTFSI 和 $\mathrm{LiSO}_{3} \mathrm{CF}_{3}$ )、不同 TEGDME 与 DOL 比例对锂硫电池 性能的影响, 发现锂盐种类影响电解液中锂离子的传输 性能和有机电解液的黏度, 使用 LiTFSI 的电解液离子 电导率高于使用 $\mathrm{LiSO}_{3} \mathrm{CF}_{3}$ 的电解液, 但这个级别的离 子电导率差别对锂硫电池循环性能影响不大. 锂硫电池 的性能随着 TEGDME + DOL 电解液中 DOL 含量的增加 而提高, 最佳比例为 TEGDME : DOL $=15: 85$ (by volume), 首次放电比容量可达 $1000 \mathrm{mAh} / \mathrm{g}$, 继续提高 DOL 的含量后, 受限于 DOL 对 $\mathrm{Li}_{2} \mathrm{~S}_{n}(4 \leqslant n \leqslant 8)$ 的溶解 性以及其本身的易聚合性, 锂硫电池性能开始下降.

同年, Suo 等 ${ }^{[35]}$ 改变了传统 “溶剂溶盐” (Salt-inSolvent) 的有机电解液体系, 而是使用 “盐溶溶剂” (Solvent-in-Salt)的新体系用于锂硫电池. 所谓 “盐溶溶 剂” 体系, 是指在溶液中, 盐在体积比及/或质量比方面 均高于 $50 \%$, 如图 2 所示. 他们制备了摩尔浓度从 $1 \sim 7$ $\mathrm{mol} / \mathrm{L}$ 的 LiTFSI/DOL + DME (1: 1 by volume) 的 “盐溶 溶剂” 体系, 其中使用 $7 \mathrm{~mol} / \mathrm{L} \mathrm{LiTFSI} / \mathrm{DOL}+\mathrm{DME}$ 作为 有机电解液的锂硫电池充放电曲线正常, 具有较好的循 环性能和倍率性能, 在 $0.2 \mathrm{C}$ 倍率下, 首次放电比容量为 $1041 \mathrm{mAh} / \mathrm{g}, 100$ 次循环后容量保持率为 $74 \%$, 而充放 电效率则一直接近 $100 \%$. 而在 $0.5 \mathrm{C}, 1 \mathrm{C}, 2 \mathrm{C}$ 以及 $3 \mathrm{C}$ 倍 率下, 其放电比容量能分别达到 988, 864, 744 和 551 
$\mathrm{mAh} / \mathrm{g}$. 得到如此循环性能的原因是, 一方面高盐浓度 $(7 \mathrm{~mol} / \mathrm{L})$ 的 LiTFSI/DOL $+\mathrm{DME}$ 体系中锂离子的浓度接 近溶解饱和浓度, 抑制了 $\mathrm{Li}_{2} \mathrm{~S}_{n}(4 \leqslant n \leqslant 8)$ 向电解液的溶 解, 另一方面高盐浓度造成的高黏度 $(72 \mathrm{cP})$ 和高锂离子 迁移数 $(0.73)$ 能抑制已溶解于其中的 $\mathrm{Li}_{2} \mathrm{~S}_{n}(4 \leqslant n \leqslant 8)$ 向 锂负极扩散.

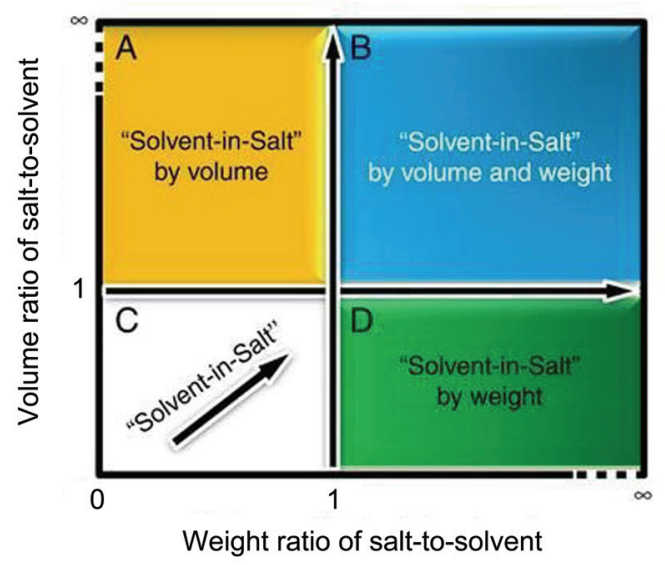

图 2 电解液 “盐溶溶剂” 体系中锂盐的质量及/或体积比例 ${ }^{[35]}$

Figure 2 The distribution map of non-aqueous liquid electrolytes with the weight and volume ratios of salt-to-solvent ${ }^{[35]}$

从上述研究中可以看出, 采用普通的链状醚类与环 状醚类的混合溶剂作为锂硫电池的电解液, 仅能解决锂 硫电池基本的正常充放电问题, 使电池在首次放电中达 到较高的放电比容量, 但由 $\mathrm{Li}_{2} \mathrm{~S}_{n}(4 \leqslant n \leqslant 8)$ 的溶解及其 向负极的扩散带来的循环问题难以仅靠这类混合溶剂 解决.

随着室温离子液体作为绿色溶剂而被广泛关注, 研 究者们也将离子液体引入锂硫电池中, 其主要目的是利 用离子液体的高黏度减少 $\mathrm{S}_{n}^{2-}(4 \leqslant n \leqslant 8)$ 向锂负极的扩 散, 而锂离子在其中的传输不受影响, 最终提高锂硫电 池的循环性能 ${ }^{[36,37]}$.

2006 年, Yuan 等 ${ }^{[38]}$ 合成了室温离子液体 $N$-甲基- $N$ 丁基-哌啶(PP14)双(三氟甲基磺酰)(TFSI)铵盐, 并配成 $1 \mathrm{~mol} / \mathrm{L} \mathrm{LiTFSI} / \mathrm{PP} 14-\mathrm{TFSI}$ 溶液作为锂硫电池的电解液. 该电解液的室温离子电导率达到 $2.2 \times 10^{-3} \mathrm{~S} / \mathrm{cm}$, 使用 该电解液的锂硫电池首次放电比容量达到了 1055 $\mathrm{mAh} / \mathrm{g}$, 循环 10 次后, 其容量保持在 $750 \mathrm{mAh} / \mathrm{g}$.

2012 年, Wen 等 ${ }^{[39]}$ 同样合成了室温离子液体

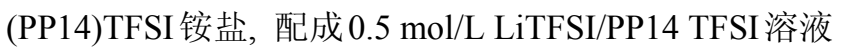
作为锂硫电池的电解液. 配合 PVdF 基凝胶电解质使用, 该锂硫电池有较高的首次放电比容量, 达 $1218 \mathrm{mAh} / \mathrm{g}$, 20 次循环后容量保持在 $818 \mathrm{mAh} / \mathrm{g}$.

2013 年, Byon 等 ${ }^{[40]}$ 合成了室温离子液体 $N$-甲基- $N$ 丙基-哌啶(PP13) TFSI 铵盐, 并与 DME 混合, 配制成 1 mol/L LiTFSI/(PP13)TFSI+DME (2: 1 by volume)溶液 作为锂硫电池的有机电解液, 该锂硫电池在 $0.2 \mathrm{C}$ 倍率
下首次放电比容量约 $1000 \mathrm{mAh} / \mathrm{g}, 50$ 次循环后容量保持 率达 $90 \%$, 表现出很好的循环性能.<smiles>CCCC[N+]1(C)CCCCC1</smiles>

图 3 PP14 和 PP13 的化学结构式

Figure 3 Structural formula of PP14 and PP13

2013 年, Watanabe 研究小组 ${ }^{[36]}$ 合成了 $N, N$-二乙基$N$-甲基- $N$-(2-甲氧基)铵(DEME) TFSI 盐，并配成 0.64 $\mathrm{mol} / \mathrm{L} \mathrm{LiTFSI} /(\mathrm{DEME}) \mathrm{TFSI}$ 溶液作为电解液用于锂硫电 池, 研究了锂硫电池在其中的电化学反应. 研究表明, 在该离子液体中锂硫电池充放电行为正常, 循环性能更 是远优于使用 $0.96 \mathrm{~mol} / \mathrm{L} \mathrm{LiTFSI} / \mathrm{TEGDME}$ 电解液的锂 硫电池. 经红外-可见光光谱、XRD 等方法测试后表明, 离子液体能有效抑制 $\mathrm{S}_{n}^{2-}$ 的溶解及扩散. 同年，该研究 小 组 ${ }^{[41]}$ 又合成了一系列不同阴离子的聚乙烯醚锂类 ([Li(glyme) $] \mathrm{X}$ )离子液体, 其中阴离子 $\mathrm{X}$ 分别为双(五氟 乙基磺酰亚胺)负离子 $\left[{ }^{-} \mathrm{N}\left(\mathrm{SO}_{2} \mathrm{C}_{2} \mathrm{~F}_{5}\right)_{2}, \mathrm{BETI}^{-}\right]$、双(三氟甲 基磺酰亚胺)负离子 $\left[{ }^{-} \mathrm{N}\left(\mathrm{SO}_{2} \mathrm{CF}_{3}\right)_{2}, \mathrm{TFSI}^{-}\right]$、三氟甲基磺 酸负离子 $\left(\mathrm{SO}_{3} \mathrm{CF}_{3}, \mathrm{OTF}^{-}\right)$、四氟硼酸负离子 $\left(\mathrm{BF}_{4}^{-}\right)$、硝 酸负离子 $\left(\mathrm{NO}_{3}^{-}\right)$等, 将它们作为有机电解液用于锂硫 电池, 并研究了不同阴离子对锂硫电池性能的影响. 研 究发现, $\mathrm{NO}_{3}^{-}$在锂硫电池放电过程中不可逆地减少, $\mathrm{BF}_{4}^{-}$在锂硫电池放电过程中与 $\mathrm{Li}_{2} \mathrm{~S}_{n}(4 \leqslant n \leqslant 8)$ 发生不良 的副反应. 分别使用含 $\mathrm{BETI}^{-}$和 $\mathrm{TFSI}^{-}$作为有机电解液 的锂硫电池 100 次循环后放电比容量稳定在约 600 $\mathrm{mAh} / \mathrm{g}$, 库仑效率超过 $98.5 \%$, 性能优于使用普通有机 电解液的锂硫电池.

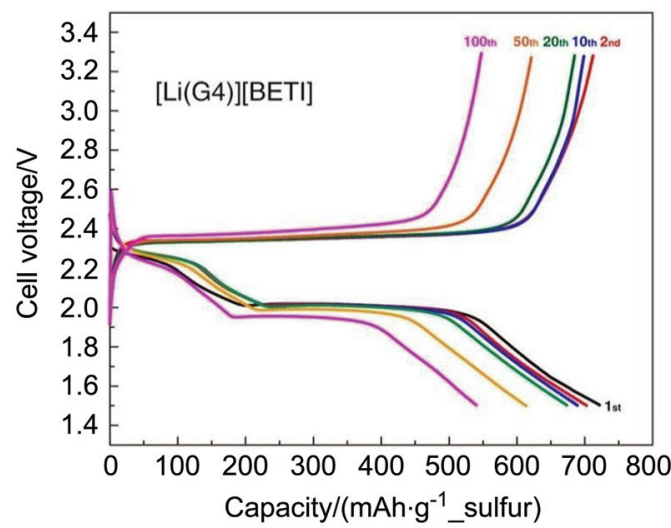

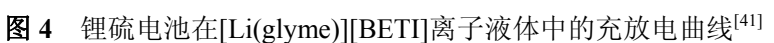
Figure 4 Charge/discharge curves of $\mathrm{Li}$-[Li(glyme)][BETI]-S cells ${ }^{[4]}$

以上的研究表明, 室温离子液体能在一定程度上改 善锂硫电池的循环性能, 作为锂硫电池电解液具有潜在 的应用前景. 但是，由于室温离子液体的合成工艺复杂， 成本较高等原因，尚未处于实验室研究阶段. 


\section{3 电解液添加剂}

在早期的研究中, 由于对锂硫电池的充放电原理尚 处于探索阶段, 因此研究人员对使用何种有机电解液都 未达成共识, 对电解液添加剂的研究更是甚少. 只有 20 世纪 70 年代, Eichinger 等 ${ }^{[42,43]}$ 尝试使用 $N, N$-二甲基甲酰 胺 $(\mathrm{DMF})$ 电解液中添加 Lewis 酸 $\mathrm{BF}_{3}$ 用于锂硫电池, 以 利用 $\mathrm{BF}_{3}$ 抑制 $\mathrm{Li}_{2} \mathrm{~S}_{n}(4 \leqslant n \leqslant 8)$ 的溶解, 但是使用该电解 液的锂硫电池并没有得到良好的性能.

在确定了使用环状醚类和链状醚类的混合溶剂作 为锂硫电池的有机电解液后, 研究人员逐渐开始研究有 效的电解液添加剂以再次提高锂硫电池的活性物质利 用率及循环性能.

2004 年, Mikhaylik 等 ${ }^{[44]}$ 提出在 DME+DOL 电解液 中添加含 $\mathrm{N}-\mathrm{O}$ 键化合物能有效提高锂硫电池正极活性 物质利用率并减少电池自放电, 其中以 $\mathrm{LiNO}_{3}$ 效果最 好. Liang ${ }^{[45]}$, Zhang 等 ${ }^{[46]}$ 以及我们研究小组 ${ }^{[47]}$ 的研究也 分别证实了在电解液中添加 $\mathrm{LiNO}_{3}$ 对改善锂硫电池循 环性能的效果. Aurbach 等 ${ }^{[48]}$ 使用电化学阻抗(EIS)、红 外光谱(FT-IR)、 $X$ 射线光电子能谱(XPS)等方法对在 $\mathrm{DME}+\mathrm{DOL}$ 电解液中添加 $\mathrm{LiNO}_{3}$ 从而改善锂硫电池性 能的机理进行了分析, 认为 $\mathrm{LiNO}_{3}$ 的主要作用是保护金 属锂负极. $\mathrm{LiNO}_{3}$ 能与电解液中 $\mathrm{DOL}$ 以及 $\mathrm{Li}_{2} \mathrm{~S}_{n}(4 \leqslant n \leqslant$ 8)反应, 在锂负极表面形成一层 SEI 钝化保护层, 以减 少锂硫电池中的飞梭现象, 其具体产物如图 5 所示. Zhang 等 ${ }^{[49]}$ 通过 CV, EIS, 充放电测试等方法研究指出, 使用含 $\mathrm{LiNO}_{3}$ 电解液的锂硫电池放电终止电压不宜过 低, 否则该 SEI 保护层将不可逆地被破坏, 从而在长时 间循环时无法提供持续的保护. 最适合的充放电电压区 间为 $1.8 \sim 3.0 \mathrm{~V}$. 经过近十年的研究, $\mathrm{LiNO}_{3}$ 被认为是至 今在锂硫电池有机电解液中最有效的添加剂, 对其的研 究及应用仍在不断继续.

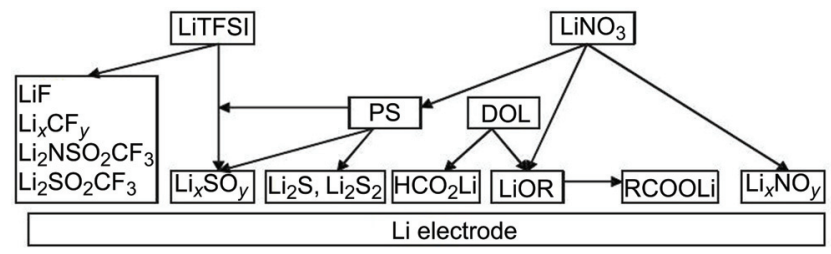

图 5 锂负极在 $\mathrm{DOL} / \mathrm{LiTFSI}+\mathrm{Li}_{2} \mathrm{~S}_{6}+\mathrm{LiNO}_{3}$ 溶液中多种产物示意 图 $^{[48]}$

Figure 5 The contribution of the various components in DOL/LiTFSI+ $\mathrm{Li}_{2} \mathrm{~S}_{6}+\mathrm{LiNO}_{3}$ solutions to the surface chemistry of Li electrodes ${ }^{[48]}$

除此之外, 还有其它不同类型的电解液添加剂被研 究.

2008 年, Choi 等 ${ }^{[29,50]}$ 研究了基于不同溶剂组成 (DME, DG, TEGDME, DOL) 的电解液对锂硫电池的电 化学性能的影响, 并研究了不同的有机添加剂 $[\gamma-$ 丁内 酯(GBL)、乙酸甲酯(MA)和 TOL]对循环性能的影响. 其 中, 在 $1 \mathrm{~mol} / \mathrm{L} \mathrm{LiCF}_{3} \mathrm{SO}_{3} / \mathrm{TEGDME}$ 电解液中加入 $5 \mathrm{wt} \%$
TOL 效果最好. TOL 的加入能降低电解液黏度, 改善了 循环过程中硫正极的表面形貌，有效提高活性物质的利 用率，相较于使用未添加 TOL 电解液的锂硫电池，使用 含 $5 \mathrm{wt} \% \mathrm{TOL}$ 电解液的锂硫电池首次放电比容量提高 了 1.8 倍.

2011 年, Trofimov 等 ${ }^{[51]}$ 合成了一系列两端为有机基 团的聚硫化合物, 其中当分别使用含 $5 \mathrm{wt} \%$ 化学式如图 6 所示的两种聚硫化合物的有机电解液的锂硫电池, 50 次循环后的放电比容量相比较于未使用添加剂的有机 电解液(2 mol/L LiTFSI/DME+DOL) 时分别提高了 $35 \%$ 和 $25 \%$. 其原因是该聚硫化合物能与不溶于有机电解液 的 $\mathrm{Li}_{2} \mathrm{~S}_{2}$ 和 $\mathrm{Li}_{2} \mathrm{~S}$ 反应，从而促进其溶解，反应式如图 6 所示.

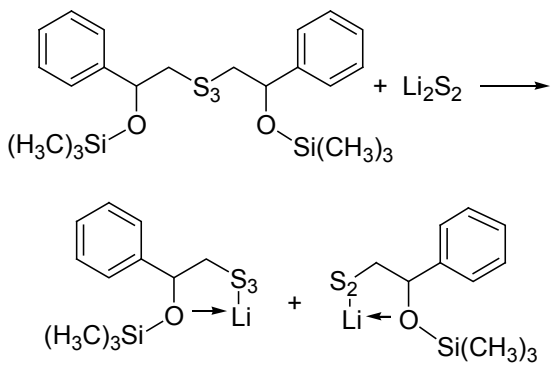<smiles>COC(CSCC(O[SiH3])c1ccccc1)c1ccccc1</smiles>

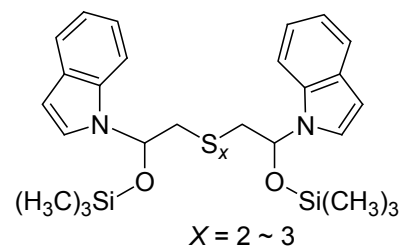

(b)

图 6 聚硫化合物化学结构式 ${ }^{[51]}$

Figure 6 Chemical formula of bis(hydroxyorganyl) polysulfide ${ }^{[51]}$

2011 年, 我们研究小组 ${ }^{[52]}$ 研究了在有机电解液中 不同含量的双草酸硼酸锂( $\mathrm{LiBOB})$ 对锂硫电池循环性能 的影响. 在有机电解液 $1 \mathrm{~mol} / \mathrm{L} \mathrm{LiTFSI/DOL}+\mathrm{DME}$ 中 添加适量 $\mathrm{LiBOB}$ 后, 锂硫电池的放电比容量、库伦效率 及循环性能均有所提高, 其原因是 $\mathrm{LiBOB}$ 同样能在锂 负极表面形成一层钝化保护层.

2012 年, Liang 等 ${ }^{[53]}$ 研究发现在电解液中添加 $\mathrm{P}_{2} \mathrm{~S}_{5}$ 能显著改善锂硫电池的循环性能. 在 $1 \mathrm{~mol} / \mathrm{L} \mathrm{LiTFSI/}$ TEGDME 中添加了 $5 \mathrm{wt} \% \mathrm{P}_{2} \mathrm{~S}_{5}$ 的锂硫电池在 $0.1 \mathrm{C}$ 倍率 下 20 次循环后放电比容量容量稳定于 $900 \mathrm{mAh} / \mathrm{g}$, 直至 40 次循环放电比容量也未见明显衰减, 而库伦效率则 一直保持在 $90 \%$ 以上, 循环性能较未添加 $\mathrm{P}_{2} \mathrm{~S}_{5}$ 的锂硫电 池有大幅提升. 他们认为 $\mathrm{P}_{2} \mathrm{~S}_{5}$ 的作用主要在于: (1) $\mathrm{P}_{2} \mathrm{~S}_{5}$ 能够与 $\mathrm{Li}_{2} \mathrm{~S}$ 反应而促进 $\mathrm{Li}_{2} \mathrm{~S}$ 向电解液溶解, 减少因 $\mathrm{Li}_{2} \mathrm{~S}$ 沉淀而造成的活性物质的损失. (2) $\mathrm{P}_{2} \mathrm{~S}_{5}$ 能够在金属锂负 
极表面形成一层钝化保护层以减少锂硫电池中的飞梭 现象.

从上述研究可以看出, 锂硫电池电解液添加剂的主 要作用是对锂负极进行所谓的 “原位保护”, 即在电池 放电过程中添加剂与放电中间产物及金属锂反应, 在锂 负极表面形成一层 SEI 钝化保护层, 从而避免 $\mathrm{Li}_{2} \mathrm{~S}_{n}$ $(4 \leqslant n \leqslant 8)$ 与锂负极的直接接触, 最终提高锂硫电池性 能. 但是, 除了 $\mathrm{LiNO}_{3}$ 被详细研究外, 其余能进行原位 保护的添加剂在锂负极表面所形成的 SEI 钝化保护膜在 长时间、高倍率下能否继续保持稳定, 还需要继续研究.

\section{4 聚合物电解质}

聚合物电解质是指通过聚合物膜和盐构成的一类 可以传输离子的新型离子导体. 聚合物电解质的研究始 于 20 世纪 70 年代, Wright ${ }^{[54]}$ 于 1975 年首先报道了 PEO 与碱金属盐的络合体系的离子导电特性, 随后 $\mathrm{Armand}^{[55]}$ 首次提议将其用作全固态电池的电解质材料. 从此, 各种不同类型的聚合物电解质的研究层出不穷. 想较于传统的液态有机电解质体系, 聚合物电解质具有 以下优点: (1)避免了电解液泄漏所造成的安全问题. (2) 易产生形变, 能保证与电极良好接触. (3)化学和电化学 稳定性好. (4)易于进行特殊要求的分子结构设计或用物 理方法对其结构进行修饰以满足各种用途的要求.

聚合物电解质按其相态可分为全固态聚合物电解 质(SPE)和凝胶聚合物电解质(GPE).

$\mathrm{SPE}$ 由高分子量聚合物基体[如聚氧化乙烯(PEO)、 聚氧化丙烯(PPO)等]和锂盐组成, 可以近似的看作是锂 盐直接溶解于聚合物基体中而形成的固态溶液体系. $\mathrm{SPE}$ 的离子电导率与聚合物基体链段的局部运动能力 密切相关, 锂离子在聚合物基体中的迁移是通过聚合物 链段的运动在其配位位置上连续反复 “配位一解配位” 而发生, 因此 SPE 的室温离子电导率偏低, 一般在 $10^{-8} \sim 10^{-7} \mathrm{~S} / \mathrm{cm}$ 之间. GPE 主要由聚合物基体[如 PEO、 聚偏氟乙烯(PVdF)、聚甲基丙烯酸甲酯(PMMA)、聚丙 烯腈(PAN)、聚偏氟乙烯一六氟丙烯(PVdF-HFP)等]、增 塑剂(一般为有机电解液)与锂盐通过互溶的方式形成具 有合适微结构的聚合物网络, 虽然体系也存在离子-离 子和离子-聚合物间复杂的相互作用, 但增塑剂对离子 的溶剂化作用占主导地位, 而聚合物对离子的复合作用 表现出较大的惰性, 离子主要利用固定在微结构中的增 塑剂实现离子传导, 其离子传导机理类似于液体中离子 的传导机理, 因此室温离子电导率也较高, 一般在 $10^{-4} \sim 10^{-3} \mathrm{~S} / \mathrm{cm}$ 之间.

在锂硫电池中, 研究人员引入聚合物电解质以替代 传统的液态电解液, 期望在改善锂硫电池安全性的同 时, 通过聚合物的物理隔绝控制 $\mathrm{Li}_{2} \mathrm{~S}_{n}(4 \leqslant n \leqslant 8)$ 向锂负 极的扩散, 从而提高锂硫电池的性能.

\section{1 全固态聚合物电解质}

2002 年, $\mathrm{Kim}$ 研究小组 ${ }^{[56]}$ 制备了 $(\mathrm{PEO})_{10} \mathrm{LiCF}_{3} \mathrm{SO}_{3}$ 型 $\mathrm{SPE}$, 并添加了 $\mathrm{Ti}_{n} \mathrm{O}_{2 n-1}(n=1,2)$ 以提高聚合物电解 质的离子电导率, 研究了该 SPE 的离子电导率、与锂负 极的界面稳定性, 最后应用于锂硫电池测试了电池的放 电性能. 研究发现, 在该 SPE 中添加钛氧化物能有效提 高聚合物电解质的室温离子电导率和锂离子迁移数, 并 显著减少聚合物电解质与锂负极之间的界面阻抗. 使用 该 SPE 的锂硫电池在 $90{ }^{\circ} \mathrm{C}$ 下以 $0.14 \mathrm{~mA} / \mathrm{cm}^{2}$ 的电流密 度放电, 放电平台有所下降 (接近 $2.0 \mathrm{~V})$, 放电比容量较 高, 使用添加了 $15 \mathrm{wt} \% \mathrm{Ti}_{n} \mathrm{O}_{2 n^{-1}}(n=1,2) \mathrm{SPE}$ 的锂硫电 池首次放电比容量甚至接近理论容量, 达 $1600 \mathrm{mAh} / \mathrm{g}$ 以上, 循环性能不佳, 10 次循环后容量保持率仅为 $40 \%$. 2007 年，该研究小组 ${ }^{[57]}$ 又通过 3 种不同的混合方式制备 了 $(\mathrm{PEO})_{6} \mathrm{LiBF}_{4}$ 型 $\mathrm{SPE}$, 并应用于锂硫电池. 锂硫电池在 $80{ }^{\circ} \mathrm{C}$ 下以 $0.07 \mathrm{~mA} / \mathrm{cm}^{2}$ 的电流密度放电, 其中使用球磨 法制得的含 $10 \mathrm{wt} \% \mathrm{Al}_{2} \mathrm{O}_{3}$ 的 $\mathrm{SPE}$ 性能最好, 首次放电比 容量达 $1670 \mathrm{mAh} / \mathrm{g}$, 达到单质硫的理论比容量, 但循环 性能依然没能改善, 10 次循环后容量保持率为 $40 \%$.

2005 年, Wen 研究小组 ${ }^{[58]}$ 将含 (PEO) ${ }_{20}$ LiTFSI-10 $\mathrm{wt} \% \gamma-\mathrm{LiAlO}_{2}$ 型 $\mathrm{SPE}$ 应用于锂硫电池, $75{ }^{\circ} \mathrm{C}$ 下以 0.1 $\mathrm{mA} / \mathrm{cm}^{2}$ 的电流密度放电, 首次放电比容量仅 450 $\mathrm{mAh} / \mathrm{g}$, 经 50 次循环以后电池循环容量仅剩 $290 \mathrm{mAh} / \mathrm{g}$. 2011 年, 该研究小组 ${ }^{[59]}$ 进一步将(PEO) ${ }_{18}$ LiTFSI-10 wt $\%$ $\mathrm{SiO}_{2}$ 型 $\mathrm{SPE}$ 用于正极材料为硫/介孔碳球的锂硫电池中. 该电池有较好的循环性能, 在 $75{ }^{\circ} \mathrm{C}$ 下以 $0.1 \mathrm{~mA} / \mathrm{cm}^{2}$ 的 电流密度放电, 首次放电比容量为 $1265 \mathrm{mAh} / \mathrm{g}$, 经 25 次循环以后电池循环容量仍有 $800 \mathrm{mAh} / \mathrm{g}$.

2010 年, Scrosati 等 ${ }^{[60]}$ 将 $\mathrm{PEO}-\mathrm{LiCF}_{3} \mathrm{SO}_{3}+\mathrm{ZrO}_{2}$ 型 SPE 用于锂硫电池，在不同温度下以不同倍率放电，其 中以 $\mathrm{C} / 20$ 倍率放电, $70{ }^{\circ} \mathrm{C}$ 下放电比容量小于 400 $\mathrm{mAh} / \mathrm{g}, 80{ }^{\circ} \mathrm{C}$ 则可高于 $900 \mathrm{mAh} / \mathrm{g}$.

以上研究表明, 使用 SPE 的锂硫电池在某些情况下 能得到较好的性能, 但受限于 SPE 的室温电导率, 这些 电池普遍需要在较高的温度下才能正常工作, 基本未见 使用 SPE 的锂硫电池在室温下工作的报道, 因此其应用 范围大大受限，近年来少有对该方面的报道. 若能将离 子电导率提高到 $10^{-4}$ 数量级, SPE 将在锂硫电池甚至传 统的锂离子电池的应用中大有前景 ${ }^{[61]}$.

\section{2 凝胶聚合物电解质}

在保留 SPE 诸多优点的条件下, 为提高其离子电导 率, Feuillade 等 ${ }^{[62]}$ 于 1975 年提出可在 SPE 中加入增塑剂 形成 GPE, 可以大幅提高电解质的离子电导率. 聚合物 凝胶并不是聚合物溶解于增塑剂中形成高分子溶液, 而 是增塑剂溶解于聚合物中形成的体系，在该体系中，不 仅聚合物是连续相, 增塑剂也是连续相. 从严格意义来 看, GPE 可以看作是 SPE 和液态电解质的中间妥协状态, 并不是锂离子电池中的最佳材料，但在没有更好的新体 
系出现之前, GPE 仍是比较理想的选择.

随着对 GPE 广泛而深入的研究, GPE 也越来越多的 应用于锂硫电池, 其体系主要包括 PEO, PVdF, PVdF-HFP 等.

2002 年, Chung 等 ${ }^{[63]}$ 将 $\mathrm{PEO}$ 与 $\mathrm{LiClO}_{4}$ 溶解于 TEGDME 与乙腈的混合溶剂中, 流延于 Teflon 平板上, 待乙腈完全挥发后得到 $\mathrm{LiClO}_{4}$-PEO/TEGDME 型 GPE. 虽然使用该 GPE 的锂硫电池没有得到较好的性能, 但 是他们通过对循环过程中硫正极的 SEM 分析, 提出了 在循环过程中硫正极的形貌变化模型, 认为硫在充电过 程中存在在正极骨架里分配不均匀的现象, 这是造成电 池容量衰减的原因之一, 这一现象也与使用液态电解质 的锂硫电池的正极形貌变化基本一致.

同年, Shin 等 ${ }^{[64]}$ 分别采用摚拌法和球磨法制得 PVdF-HFP 基 GPE 用于锂硫电池, 其中 TEGDME 为增 塑剂, $\mathrm{LiCF}_{3} \mathrm{SO}_{3}, \mathrm{LiBF}_{4}$ 和 $\mathrm{LiPF}_{6}$ 分别作为锂盐. 其中采 用球磨法制得的 GPE 性能普遍高于采用搅拌法制得的 GPE, 其原因是球磨法能有效降低 GPE 的结晶度. 使用 该 GPE 的锂硫电池在常温下以 $0.14 \mathrm{~mA} / \mathrm{cm}^{2}$ 的电流密度 放电, 性能最好的首次放电比容量超过 $1500 \mathrm{mAh} / \mathrm{g}$, 但 10 次循环后容量保持率仅为 $38 \%$.

Wang 等 ${ }^{[65,66]}$ 于 2002 年和 2003 年将 PVdF 基 GPE 分别应用于正极材料为多孔碳/硫复合材料和 PAN/硫复 合材料的锂硫电池中, 其中增塑剂为 PC-EC-DEC(体积 比为 $1: 4: 5)$, 锂盐为 $\mathrm{LiPF}_{6}$. 使用多孔碳/硫复合材料 作为正极的锂硫电池在室温下以 $0.3 \mathrm{~mA} / \mathrm{cm}^{2}$ 的电流密 度放电可得到可逆容量为 $440 \mathrm{mAh} / \mathrm{g}$; 使用 $\mathrm{PAN} /$ 硫复 合材料作为正极的锂硫电池首次放电比容量为 850 $\mathrm{mAh} / \mathrm{g}, 50$ 次循环后放电比容量仍高于 $600 \mathrm{mAh} / \mathrm{g}$.

2003 年, Park 等 ${ }^{[67]}$ 首先使用紫外光引发 PEGDME 在锂负极表面聚合, 以形成保护层抑制 $\mathrm{Li}_{2} \mathrm{~S}_{n}(4 \leqslant n \leqslant 8)$ 与金属锂的直接反应, 然后在锂硫电池中使用 $\mathrm{LiClO}_{4}-\mathrm{PVdF}-\mathrm{HFP} / \mathrm{TEGDME}$ 型 GPE. 其中, 锂负极表面 的聚合物保护层也可看作是另一层 GPE. 对比使用液态 电解质以及未存在锂负极保护层的锂硫电池, 发现 GPE 和负极表面聚合物保护层能有效提高锂硫电池的循环 性能, 100 次循环后放电比容量从 $270 \mathrm{mAh} / \mathrm{g}$ 提高到 417 $\mathrm{mAh} / \mathrm{g}$.

2006 年, Ryu 等 ${ }^{[68]}$ 使用 THF 溶解 PVdF, 采用流延 法制得 PVdF 自撑膜, 然后加入增塑剂制成 $\mathrm{LiCF}_{3} \mathrm{SO}_{3}$ PVdF/TEGDME 型 GPE, 用于锂硫电池并详细分析了电 池的放电过程. 该研究认为, 使用 GPE 的锂硫电池与使 用有机液态电解质的锂硫电池的放电过程区别不大, 在 高电压平台单质硫 $\mathrm{S}_{8}$ 被还原为 $\mathrm{Li}_{2} \mathrm{~S}_{n}(4 \leqslant n \leqslant 8)$, 在低电 压平台 $\mathrm{Li}_{2} \mathrm{~S}_{n}(4 \leqslant n \leqslant 8)$ 继续被还原为 $\mathrm{Li}_{2} \mathrm{~S}$. 使用该 $\mathrm{GPE}$ 的锂硫电池首次放电比容量达 $1268 \mathrm{mAh} / \mathrm{g}$, 但第二次 循环后容量就降至 $1028 \mathrm{mAh} / \mathrm{g}$, 且高电压放电平台消 失, 其原因是在电解液中的 $\mathrm{Li}_{2} \mathrm{~S}_{n}(4 \leqslant n \leqslant 8)$ 难以被完全 氧化回到 $\mathrm{S}_{8}$.
2013 年, Chen 等 ${ }^{[69]}$ 使用 PMMA 与 PVdF 共混制得 GPE，并加入三甲氧基甲硅烷以提高离子电导率和锂离 子迁移数. 使用该 GPE 的锂硫电池 100 次循环后可逆比 容量仍达 $1050 \mathrm{mAh} / \mathrm{g}$, 为首次放电比容量的 $88 \%$. 但由 于该 GPE 的锂离子迁移数为 0.457 , 其平均孔径为 0.064 $\mathrm{mm}$, 并不足以阻止 $\mathrm{S}_{n}^{2-}$ 的通过, 因此其原理需要进一步 研究.

近年来, 研究人员们逐渐认识到, 传统 GPE 中聚合 物基体与离子间的相互作用力很弱, 其锂离子传导主要 通过增塑剂来实现，离子传导机理与液态电解质相近， 因此在锂硫电池中难以抑制 $\mathrm{S}_{n}^{2-}(4 \leqslant n \leqslant 8)$ 向锂负极的 扩散. 本研究小组提出可以通过对聚合物结构的设计, 使用具有单阳离子传导的 GPE, 使其中锂离子的迁移数 达到 1 . 当电解质的锂离子迁移数为 1 时, 意味着电解 质中的电荷传导全部由锂离子的迁移所带来, 负离子将 无法在电解质内部迁移, 这样溶解于电解液中的 $\mathrm{Li}_{2} \mathrm{~S}_{n}$ $(4 \leqslant n \leqslant 8)$ 仅在正极区域附近进行电化学反应, 而无法 通过 GPE 扩散至锂负极, 其原理示意图如图 7 所示. 其 中增塑剂(液态电解质)能够溶解 $\mathrm{Li}_{2} \mathrm{~S}_{n}(4 \leqslant n \leqslant 8)$, 保证 了锂硫电池较高的放电比容量; 锂离子的迁移数为 1 的 GPE 抑制了 $\mathrm{S}_{n}^{2-}(4 \leqslant n \leqslant 8)$ 向锂负极的扩散, 将有效提 高锂硫电池的循环性能和库仑效率.

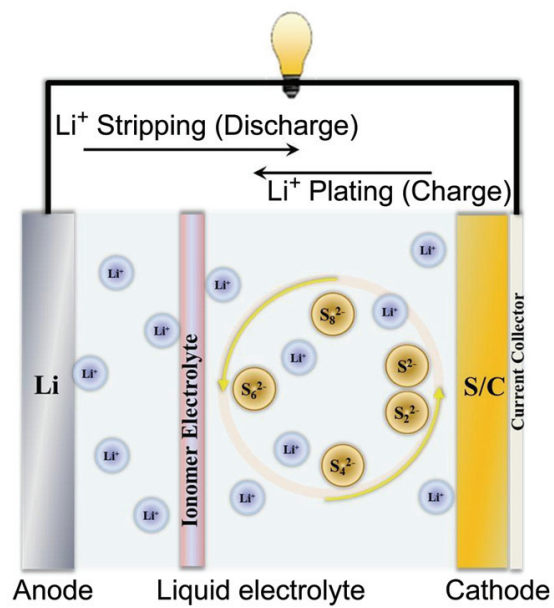

图 7 锂硫电池使用单阳离子传导 GPE 的原理示意图

Figure 7 Schematic diagram illustrating the concept of Li-ionomer electrolyte-S batteries, in which the PS anions could dissolve in liquid electrolyte but couldn't diffuse to Li anode

我们研究小组 ${ }^{[70,71]}$ 分别制备了 PEG 型 GPE 并添加 了有机 Lweis 酸 PEG-B 以提高锂离子迁移数, 然后浸入 $1 \mathrm{~mol} / \mathrm{L} \mathrm{LiTFSI} / \mathrm{DOL}+\mathrm{DME}(1: 2$ by weight)电解液中 得到 GPE. 使用该 GPE 的锂硫电池在前 30 次循环中表 现出稳定的循环性能, 放电比容量保持在 $850 \mathrm{mAh} / \mathrm{g}$, 但之后放电比容量逐渐衰减. 经 EIS, XRD, XPS 分析发 现, 该 GPE 能减缓 $\mathrm{S}_{n}^{2-}(4 \leqslant n \leqslant 8)$ 向锂负极的扩散速度, 却无法完全阻止其向锂负极的扩散，其原因是 PEG-B 的加入虽然能提高该 GPE 的锂离子迁移数, 但该 GPE 的锂离子迁移数最高时为 0.86 , 未能达到 1 , 因此无法 
完全阻止 $\mathrm{S}_{n}^{2-}(4 \leqslant n \leqslant 8)$ 向锂负极的扩散.

2012 年, 我们研究小组 ${ }^{[72]}$ 借鉴然料电池中具有单 离子传导性的质子交换膜, 将锂化的全氟磺酸膜 (Li-PFSA)浸入 $1 \mathrm{~mol} / \mathrm{L}$ LiTFSI/DOL +DME $(1: 2$ by weight)制得 Li-PFSA 型 GPE, 并应用于锂硫电池. 经测 试, Li-PFSA 型 GPE 的锂离子迁移数达 0.986, 意味着 $\mathrm{S}_{n}^{2-}(4 \leqslant n \leqslant 8)$ 难以穿过该 GPE 而继续向锂负极扩散. 使用该 GPE 的锂硫电池首次放电比容量达 $1185 \mathrm{mAh} / \mathrm{g}$, 50 次循环后放电比容量仍有 $815 \mathrm{mAh} / \mathrm{g}$.

由于 Li-PFSA 型 GPE 的离子电导率偏低 $\left(2.1 \times 10^{-5}\right.$ $\mathrm{S} / \mathrm{cm}), 2013$ 年, 我们研究小组 ${ }^{[73,74]}$ 通过对聚合物结构的 设计, 对全氟磺酸的末端基团进行改性, 制备了全氟双 腈胺锂膜(Li-PFSD), 并浸入 $1 \mathrm{~mol} / \mathrm{L} \mathrm{LiTFSI/DOL+}$ DME (1 : 2 by weight)制得 Li-PFSD 型 GPE. Li-PFSD 型 GPE 的锂离子迁移数达 0.986 , 离子电导率为 $1.2 \times 10^{-4}$ $\mathrm{S} / \mathrm{cm}$, 用于锂硫电池时, 循环性能与使用 Li-PFSA 型 GPE 的锂硫电池相似, 但倍率性能更好, 其充放电曲线 如图 8 所示. 通过对循环后锂负极的表面分析, 可以发 现经 100 次循环后仅有较少的 $\mathrm{S}_{n}^{2-}(4 \leqslant n \leqslant 8)$ 穿过该 GPE 沉积于锂负极表面.

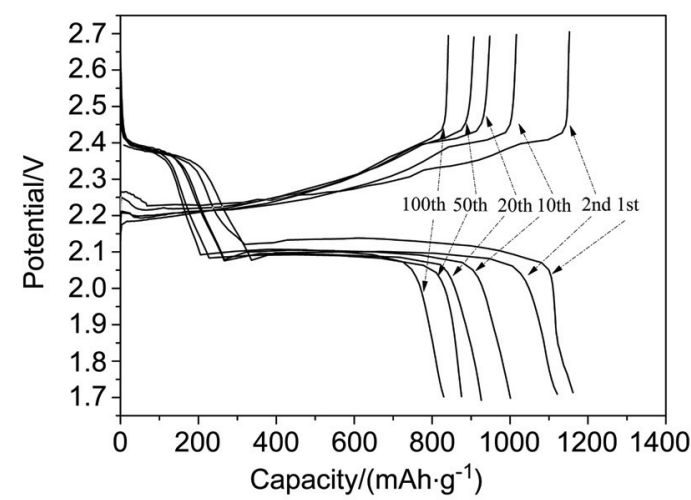

图 8 使用 Li-PFSD 型 GPE 的锂硫电池的充放电曲线 ${ }^{[73,74]}$ Figure 8 Charge/discharge curves of Li-Li-PFSD-S cells ${ }^{[73,74]}$

\section{5 无机固体电解质}

无机固体电解质又称快离子导体, 包括晶态电解质 (又称陶瓷电解质) 和非晶态电解质 (又称玻璃电解质). 该类材料有较高的室温离子电导率 $\left(>10^{-3} \mathrm{~S} / \mathrm{cm}\right)$ 和锂离 子迁移数 $(\approx 1)$, 电导活化能低, 在高能量密度的动力电 池中有很好的应用前景, 因此, 近年来无机固体电解质 得到了飞速发展. 在锂硫电池中, 无机固体电解质的作 用是作为物理屏蔽层保护锂负极, 可以完全阻隔 $\mathrm{S}_{n}^{2-}$ $(4 \leqslant n \leqslant 8)$ 向金属锂负极的扩散.

美国 Polyplus 公司在无机固体电解质保护锂负极方 面的研究最具代表性 ${ }^{[75 ~ 80]}$. 该公司研究人员从 2001 年 起就开始采用等离子体辅助沉积、蒸镀等多种技术分别 将离子传导层(一般是含有 $\mathrm{P}_{2} \mathrm{O}_{5}, \mathrm{SiO}_{2}, \mathrm{Al}_{2} \mathrm{O}_{3}$ 等成分的玻 璃一陶瓷电解质)与和金属锂相容性较好的过渡层(如 LiI,
$\mathrm{Li}_{3} \mathrm{~N}, \mathrm{Li}-\mathrm{Sn}, \mathrm{Li}-\mathrm{Cu}$ 等)沉积制备在金属锂表面，从而在 金属锂表面形成多层复合膜结构，以阻隔金属锂与电解 液直接接触. 但这种方法需要预先对金属锂表面进行平 滑和清洁处理，由于各功能层性能各异，制备过程中往 往还要添加多个过渡层以确保各层之间的相容性. 这不 但增加了电池内阻不利于负极界面电荷迁移，且制备工 艺复杂, 不利于锂硫电池商品化发展, 因此目前对采用 这种经 “保护” 的金属锂负极组装的锂硫电池充放电性 能鲜有报道.

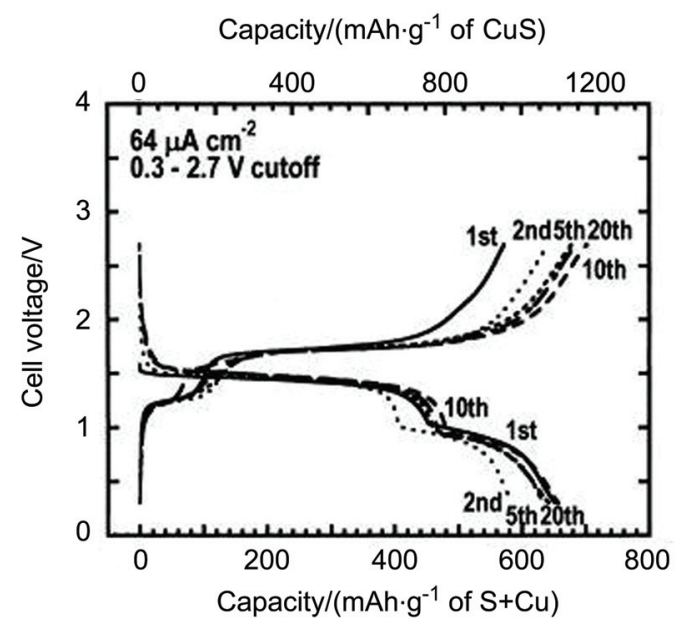

图 9 使用 $\mathrm{Li}_{2} \mathrm{~S}-\mathrm{P}_{2} \mathrm{~S}_{5}$ 玻璃陶瓷电解质的锂硫电池的充放电曲线 ${ }^{[81]}$ Figure 9 Cycling performance of an all-solid-state cell Li-In/ $80 \mathrm{Li}_{2} \mathrm{~S} \cdot 20 \mathrm{P}_{2} \mathrm{~S}_{5}$ glass-ceramic/sulfur-based mixture ${ }^{[81]}$

2003 年, Hayashi 研究小组 ${ }^{[81]}$ 采用高温固相合成法 在 $230{ }^{\circ} \mathrm{C}$ 下制得 $\mathrm{Li}_{2} \mathrm{~S}-\mathrm{P}_{2} \mathrm{~S}_{5}$ 玻璃陶瓷电解质, 并使用该 玻璃陶瓷电解质, 以 $\mathrm{S} / \mathrm{CuS}$ 为正极、 $\mathrm{Li}-\mathrm{In}$ 合金为负极组 装成全固态锂硫电池, 在 $0.064 \mathrm{~mA} / \mathrm{cm}^{2}$ 放电电流密度 下，循环性能最好的是经 20 次循环后保持有 $650 \mathrm{mAh} / \mathrm{g}$ 的放电比容量，其充放电曲线如图 9 所示. 2004 年，该 研究小组 ${ }^{[82]}$ 在此基础上研究了 $\mathrm{S} / \mathrm{CuS}$ 正极中 $\mathrm{S} / \mathrm{Cu}$ 比例 对电池性能的影响, 并研究了电池充放电机理. S/CuS 正极中 $\mathrm{Cu}$ 同样参与电化学反应, 充放电产物分别对应 为 $\mathrm{CuS}$ 和 $\mathrm{Cu}$, 因此该锂硫电池放电平台偏低分别为 1.5 和 1 V. 2011 年, 该研究小组 ${ }^{[83]}$ 采用高能球磨法制得 $\mathrm{Li}_{2} \mathrm{~S}-\mathrm{P}_{2} \mathrm{~S}_{5}$ 玻璃陶瓷电解质，并使用该玻璃陶瓷电解质， 以传统碳/硫复合材料为正极、 Li-In 合金为负极组成全 固态锂硫电池，考察了- $20 \sim 80{ }^{\circ} \mathrm{C}$ 温度范围内该电池 的性能, 其中在常温下 200 次循环后该电池的可逆容量 仍高达 $850 \mathrm{mAh} / \mathrm{g}$.

2003 年, Machida 等 ${ }^{[84]}$ 用高能球磨法制备了 $60 \mathrm{Li}_{2} \mathrm{~S}-40 \mathrm{SiS}_{2}$ 玻璃电解质, 将其与球磨得到的 $\mathrm{Cu} / \mathrm{S}$ 复 合材料正极、 $\mathrm{Li}_{4.4} \mathrm{Ge}$ 负极组装成锂硫电池，在 0.64 $\mathrm{mA} / \mathrm{cm}^{2}$ 放电电流密度下首次放电比容量大于 980 $\mathrm{mAh} / \mathrm{g}$.

2008 年, Kanno 研究小组 ${ }^{[85}$ 使用 $\mathrm{Li}_{3.25} \mathrm{Ge}_{0.25} \mathrm{P}_{0.75} \mathrm{~S}_{4}$ 陶瓷电解质，以传统硫/乙炔黑复合材料为正极，金属锂 
为负极组装成锂硫电池, 在 $0.13 \mathrm{~mA} / \mathrm{cm}^{2}$ 放电电流密度 下首次放电比容量达 $650 \mathrm{mAh} / \mathrm{g}$, 经 10 次循环以后容量 为 $370 \mathrm{mAh} / \mathrm{g} .2013$ 年, 该研究小组 ${ }^{[86]}$ 又使用同样的陶 瓷电解质, 以硫/CMK-3 复合材料为正极, 金属锂为负 极组装成锂硫电池, 在 $0.13 \mathrm{~mA} / \mathrm{cm}^{2}$ 放电电流密度下首 次放电比容量高达 $3239 \mathrm{mAh} / \mathrm{g}$, 甚至超过了硫的理论 克容量, 20 次循环后电池比容量仍有 $1300 \mathrm{mAh} / \mathrm{g}, 50$ 次 循环后电池比容量仍高于 $1000 \mathrm{mAh} / \mathrm{g}$.

2013 年, Hassoun 等 ${ }^{[87]}$ 采用高能球磨法制得 $\mathrm{Li}_{2} \mathrm{~S}-\mathrm{P}_{2} \mathrm{~S}_{5}$ 玻璃电解质, 以硫/石墨烯为正极, 金属锂为负 极在 $80{ }^{\circ} \mathrm{C}$ 下以 $\mathrm{C} / 20$ 倍率放电, 循环性能稳定, 20 次循 环中放电比容量始终保持在 $400 \mathrm{mAh} / \mathrm{g}$ 左右, 以工作电 压 $2.1 \mathrm{~V}$ 计算, 该电池的能量密度高达 $840 \mathrm{Wh} / \mathrm{kg}$.

由于无机固态电解质的锂离子迁移数能接近于 1 , 理论上能完全阻隔 $\mathrm{S}_{n}^{2-}(4 \leqslant n \leqslant 8)$ 向金属锂负极的扩散, 从而使锂硫电池获得较好的循环性能. 但是由于无机固 态电解质制备复杂、机械强度低、与电极接触的界面阻 抗较大等缺点，限制了其实用性.

\section{6 展望}

经过研究人员在过去几十年的不解努力, 锂硫电池 从原理到性能都得到了飞速的发展, 特别是锂硫电池用 有机电解液, 经历了对锂硫电池原理的逐渐深入的理 解, 才确定为链状醚类与环状醚类的混合溶剂, 其后, 基于该有机电解液的电解液添加剂、聚合物电解质等都 得以被广泛研究.

但是, 由于 $\mathrm{Li}_{2} \mathrm{~S}_{n}(4 \leqslant n \leqslant 8)$ 在电解液中的溶解和扩 散, 仅仅使用链状醚类与环状醚类的混合溶剂为电解液 的锂硫电池难以达到良好的循环性能, 未来仍需对锂硫 电池电解质继续优化. 其中可行的方案之一是结合凝胶 电解质以及无机固态电解质的优点, 在锂硫电池中使用 锂离子迁移数为 1 的单离子聚合物电解质. 锂离子迁移 数为 1 可以保证完全阻隔 $\mathrm{Li}_{2} \mathrm{~S}_{n}(4 \leqslant n \leqslant 8)$ 向锂负极的扩 散, 而聚合物电解质与电极接触的界面阻抗小, 且制备 方法简单, 能够大规模产业化. 再配以经过优化的正极 导电结构, 推动锂硫电池的实用化进程, 最终作为高性 能动力电池和储能电池广泛地应用在新能源领域.

\section{作者简介}

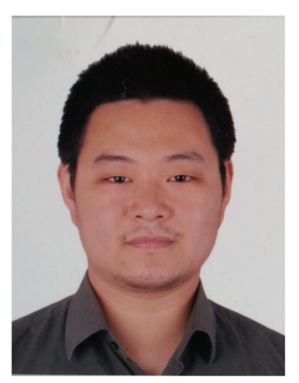

金朝庆, 国防科技大学在读博士. 2007 年于国防科技大学 航天与材料工程学院获得军用材料工程专业学士学位. 2009
年 12 月于国防科技大学航天与材料工程学院获得材料物理与 化学专业硕士学位, 2010 年 1 月至今于国防科技大学航天科学 与工程学院攻读博士学位, 师从谢凯教授, 主要研究方向为 功能型聚合物电解质和锂硫电池.

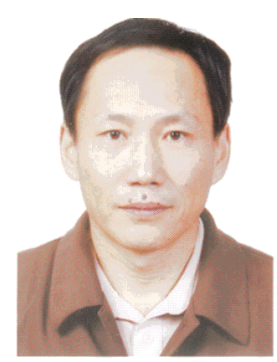

谢凯，博士生导师，教授. 1983 年毕业于浙江大学基本有 机化工专业, 获工学学士学位; 1988 年毕业于国防科技大学应 用化学专业, 获工学硕士学位. 1993 年晋升副教授, 1999 年晋 升教授. 中国材料研究学会理事, 中国空间学会理事, 享受国 务院特殊津贴的专家. 从事过的专业包括高分子材料、光电功 能材料、纳米材料、能源材料等. 现主要研究领域: 高能量密 度锂离子二次电池及材料、锂硫二次电池及材料、固体薄膜 电池、新型薄膜太阳能电池、光电功能材料等. 在国内外学术 刊物上发表论文 80 余篇, 被 SCI, EI, IAA 检索 40 余篇.

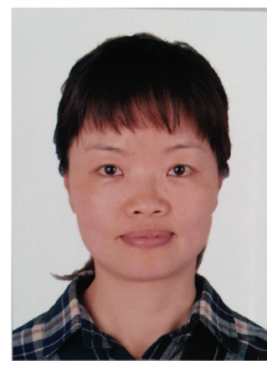

洪晓斌, 副教授. 1993 年在哈尔滨工业大学应用化学系获 得学士学位, 1996 年在航天科技集团第四研究院获得硕士学 位, 2009 年在国防科学技术大学获得博士学位, 导师谢凯教授. 主要研究领域为高性能锂硫电池, 锂电池新型聚合物电解质. 获国家发明专利 3 项, 国防发明专利 1 项, 发表学术论文 20 余篇, 参与编写专著 2 部.

\section{References}

[1] Whittingham, M. S. Chem. Rev. 2004, 104, 4271.

[2] Fergus, J. W. J. Power Sources 2010, 195, 939.

[3] Goodenough, J.; Kim, Y. Chem. Mater. 2009, 22, 587.

[4] Peramunage, D.; Licht, S. Science 1993, 261, 1029.

[5] Ji, X.; Nazar, L. F. J. Mater. Chem. 2010, $20,9821$.

[6] Akridge, J. Solid State Ionics 2004, 175, 243.

[7] Bruce, P. G.; Freunberger, S. A.; Hardwick, L. J.; Tarascon, J. M. Nat. Mater. 2012, 11, 19.

[8] Hagen, M.; Dörfler, S.; Fanz, P.; Berger, T.; Speck, R.; Tübke, J.; Althues, H.; Hoffmann, M. J.; Scherr, C.; Kaskel, S. J. Power Sources 2013, 224, 260.

[9] Zhang, S. S. J. Power Sources 2013, 231, 153

[10] Kolosnitsyn, V. S.; Karaseva, E. V. Russ. J. Electrochem. 2008, 44, 506.

[11] Mikhaylik, Y.; Akridge, J. J. Electrochem. Soc. 2004, 151, A1969.

[12] Cheon, S.; Ko, K.; Cho, J.; Kim, S. W. S.; Chin, E.; Kim, H. T. J. Electrochem. Soc. 2003, 150, A796.

[13] Dominko, R.; Demir-Cakan, R.; Morcrette, M.; Tarascon, J. M. Electrochem. Commun. 2011, 13, 117.

[14] Barchasz, C.; Molton, F.; Duboc, C.; Leprêtre, J.-C.; Patoux, S.; Alloin, F. Anal. Chem. 2012, 84, 3973. 
[15] Zhang, C.; Wu, H. Bin; Yuan, C.; Guo, Z.; Lou, X. W. D. Angew. Chem. 2012, 124, 9730.

[16] Diao, Y.; Xie, K.; Hong, X. B.; Xiong, S. Z. Acta Chim. Sinica 2013, 71, 508. (フ岩, 谢凯, 洪晓斌, 熊仕昭, 化学学报, 2013, 71, 508.)

[17] Ji, X.; Lee, K. T.; Nazar, L. F. Nat. Mater. 2009, 8, 500.

[18] Merritt, M. V.; Sawyer, D. T. Inorg. Chem. 1970, 9, 211.

[19] Martin, R. P.; Doub, W. H.; Roberts, J. L.; Sawyer, D. T. Inorg. Chem. 1973, 12, 1921.

[20] Rao, M. US 3413154, 1968 [Chem. Abstr. 1968, 70, 25241].

[21] Nole, D. US 3532543, 1970 [Chem. Abstr. 1971, 74, 18813]

[22] Rauh, R. D.; Abraham, K. M.; Pearson, G. F.; Surprenant, J. K.; Brummer, S. B. J. Electrochem. Soc. 1979, 126, 523.

[23] Yamin, H.; Peled, E. J. Electrochem. Soc. 1988, 135, 1045.

[24] Peled, E.; Sternberg, Y.; Gorenshtein, A.; Lavi, Y. J. Electrochem. Soc. 1989, 136, 1621.

[25] Chang, D.; Lee, S.; Kim, S.; Kim, H. J. Power Sources 2002, 112, 452.

[26] Barchasz, C.; Lepretre, J. C.; Patoux, S.; Alloin, F. J. Electrochem. Soc. 2013, 160, A430.

[27] Kim, S.; Jung, Y.; Lim, H. S. Electrochim. Acta 2004, 50, 889.

[28] Yuan, K. G.; Wang, A. B.; Yu, Z. B.; Wang, W. K.; Yang, Y. S. Chem. J. Chinese Univ. 2006, 27, 1738. (苑克国, 王安邦, 余仲宝, 王维 坤, 杨裕生, 高等学校化学学报, 2006, 27, 1738.)

[29] Choi, J. W.; Kima, J. K.; Cheruvally, G.; Ahn, J. H.; Ahn, H. J.; Kim, K. W. Electrochim. Acta 2007, 52, 2075.

[30] Jin, B.; Kim, J. U.; Gu, H. Bon. J. Power Sources 2003, 117, 148.

[31] Aurbach, D.; Youngman, O.; Gofer, Y.; Meitav, A. Electrochim. Acta 1990, 35, 625 .

[32] Kim, S.; Jung, Y.; Lim, H. S. Electrochim. Acta 2004, 50, 889.

[33] Wang, W.; Wang, Y.; Huang, Y.; Huang, C. J. Appl. Electrochem. 2010, 40, 321

[34] Gao, J.; Lowe, M.; Kiya, Y.; Abruña, H. D. J. Phys. Chem. C 2011, $115,25132$.

[35] Suo, L.; Hu, Y. S.; Li, H.; Armand, M.; Chen, L. Nat. Commun. 2013, 4, 1481.

[36] Park, J.-W.; Yamauchi, K.; Takashima, E.; Tachikawa, N.; Ueno, K.; Dokko, K.; Watanabe, M. J. Phys. Chem. C 2013, 117, 4431.

[37] Manan, N. S. A.; Aldous, L.; Alias, Y.; Murray, P.; Yellowlees, L. J.; Lagunas, M. C.; Hardacre, C. J. Phys. Chem. B 2011, 115, 13873.

[38] Yuan, L. X.; Feng, J. K.; Ai, X. P.; Cao, Y. L.; Chen, S. L.; Yang, H. X. Electrochem. Commun. 2006, 8, 610.

[39] Jin, J.; Wen, Z.; Liang, X.; Cui, Y.; Wu, X. Solid State Ionics 2012, $225,604$.

[40] Wang, L.; Byon, H. R. J. Power Sources 2013, 236, 207.

[41] Ueno, K.; Park, J. W.; Yamazaki, A.; Mandai, T.; Tachikawa, N.; Dokko, K.; Watanabe, M. J. Phys. Chem. C 2013, 117, 20509.

[42] Eichinger, G.; Besenhard, J. O. J. Electroanal. Chem. Interfacial Electrochem. 1976, 72, 131.

[43] Eichinger, G.; Fritz, H. P. J. Electroanal. Chem. Interfacial Electrochem. 1975, 58, 369.

[44] Mikhaylik, Y. US 7553590, 2009 [Chem. Abstr. 2009, 149, 271549].

[45] Liang, X.; Wen, Z.; Liu, Y.; Wu, M.; Jin, J.; Zhang, H.; Wu, X. J. Power Sources 2011, 196, 9839.

[46] Zhang, S. S. Electrochim. Acta 2012, 70, 344.

[47] Xiong, S.; Xie, K.; Diao, Y.; Hong, X. Electrochim. Acta 2012, 83, 78.

[48] Aurbach, D.; Pollak, E.; Elazari, R.; Salitra, G.; Kelley, C. S.; Affinito, J. J. Electrochem. Soc. 2009, 156, 694.

[49] Zhang, S. S. J. Electrochem. Soc. 2012, 159, A920.

[50] Choi, J. W.; Cheruvally, G.; Kim, D. S.; Ahn, J. H.; Kim, K. W.; Ahn, H. J. J. Power Sources 2008, 183, 441.

[51] Trofimov, B. a.; Markova, M. V.; Morozova, L. V.; Prozorova, G. F.; Korzhova, S. a.; Cho, M. D.; Annenkov, V. V.; Mikhaleva, A. I. Electrochim. Acta 2011, 56, 2458.
[52] Xiong, S.; Xie, K.; Hong, X.; Diao, Y. Ionic 2011, 18, 249.

[53] Lin, Z.; Liu, Z.; Fu, W.; Dudney, N. J.; Liang, C. Adv. Funct. Mater. 2013, 23, 1064 .

[54] Wright, P. V. Br. Polym. J. 1975, 7, 319

[55] Armand, M. Solid State Ionics 1983, 9 10, 745

[56] Shin, J. H.; Kim, K. W.; Ahn, H. J.; Ahn, J. H. Mater. Sci. Eng. B 2002, $95,148$.

[57] Jeong, S. S.; Lim, Y. T.; Choi, Y. J.; Cho, G. B.; Kim, K. W.; Ahn, H. J.; Cho, K. K. J. Power Sources 2007, 174, 745.

[58] Zhu, X.; Wen, Z.; Gu, Z.; Lin, Z. J. Power Sources 2005, 139, 269.

[59] Liang, X.; Wen, Z.; Liu, Y.; Zhang, H.; Huang, L.; Jin, J. J. Power Sources 2011, 196, 3655.

[60] Hassoun, J.; Scrosati, B. Adv. Mater. 2010, 22, 5198

[61] Manuel Stephan, Eur. Polym. J. 2006, 42, 21.

[62] Feuillade, G.; Perche, P. J. Appl. Electrochem. 1975, 5, 63.

[63] Jeon, B.; Yeon, J.; Kim, K.; Chung, I. J. Power Sources 2002, 109, 89.

[64] Shin, J. H.; Jung, S. S.; Kim, K. W.; Ahn, H. J.; Ahn, J. H. J. Mater. Sci. Mater. Electron. 2002, 13, 727.

[65] Wang, J. L.; Yang, J.; Xie, J. Y.; Xu, N. X.; Li, Y. Electrochem. Commun. 2002, 4, 499.

[66] Wang, J.; Yang, J.; Wan, C.; Du, K.; Xie, J.; Xu, N. Adv. Funct Mater. 2003, 13, 487.

[67] Lee, Y. M.; Choi, N. S.; Park, J. H.; Park, J. K. J. Power Sources 2003, 119 121,964.

[68] Ryu, H. S.; Ahn, H. J.; Kim, K. W.; Ahn, J.-H.; Lee, J.-Y. J. Power Sources 2006, 153, 360.

[69] Jeddi, K.; Ghaznavi, M.; Chen, P. J. Mater. Chem. A 2013, 1, 2769.

[70] Hu, Z. Q. Ph.D. Dissertation, National University of Defense Technology, Changsha, 2011. (胡宗倩, 博士论文, 国防科技大学, 长沙, 2011.)

[71] Jin, Z.; Xie, K.; Hong, X.; Hu, Z. J. Power Sources 2013, 242, 478.

[72] Jin, Z.; Xie, K.; Hong, X.; Hu, Z.; Liu, X. J. Power Sources 2012, 218,163

[73] Jin, Z.; Xie, K.; Hong, X. J. Mater. Chem. A 2013, 1, 342.

[74] Jin, Z.; Xie, K.; Hong, X. RSC Adv. 2013, 3, 8889.

[75] Visco, S.; Nimon, Y.; Katz, B. US 7432017, 2008 [Chem. Abstr. 2004, 140, 360340].

[76] Visco, S.; Katz, B. US 7070632, 2006, [Chem. Abstr. 2006, 145, 106844].

[77] Visco, S.; Nimon, Y.; Katz, B. US 7282296, 2007 [Chem. Abstr. 2004, 140, 126371].

[78] Visco, S.; Nimon, Y.; Katz, B. US 7390591, 2008 [Chem. Abstr. 2004, 141, 298755].

[79] Visco, S.; Tsang, F. US 6214061, 2001 [Chem. Abstr. 1999, 131, 312496].

[80] Visco, S.; Nimon, Y. US 8445362011 [Chem. Abstr. 2007, 146, 232778].

[81] Hayashi, A.; Ohtomo, T.; Mizuno, F. Electrochem. Commun. 2003, 5,701 .

[82] Hayashi, A.; Ohtomo, T.; Mizuno, F.; Tadanaga, K.; Tatsumisago, M. Electrochim. Acta 2004, 50, 893.

[83] Nagao, M.; Hayashi, A.; Tatsumisago, M. Electrochim. Acta 2011, 56,6055

[84] Machida, N.; Kobayashi, K.; Nishikawa, Y. Solid State Ionics 2004, $175,247$.

[85] Kobayashi, T.; Imade, Y.; Shishihara, D.; Homma, K.; Nagao, M.; Watanabe, R.; Yokoi, T.; Yamada, A.; Kanno, R.; Tatsumi, T. J. Power Sources 2008, 182, 621.

[86] Nagao, M.; Imade, Y.; Narisawa, H.; Kobayashi, T.; Watanabe, R.; Yokoi, T.; Tatsumi, T.; Kanno, R. J. Power Sources 2013, 222, 237.

[87] Agostini, M.; Aihara, Y.; Yamada, T.; Scrosati, B.; Hassoun, J. Solid State Ionics 2013, 244, 48. 